\title{
Derin öğrenme tabanlı iyonosferik TEC tahmini
}

\author{
İsmail Demiryege ${ }^{1}$, Mustafa Ulukavak ${ }^{*}$ (® \\ ${ }^{1}$ Harran Üniversitesi, Mühendislik Fakültesi, Harita Mühendisliği Bölümü, Şanlıurfa, Türkiye
}

\author{
Anahtar Kelimeler \\ Derin Öğrenme \\ TEC \\ GPS \\ İyonosferik Gecikme \\ LSTM
}

\begin{abstract}
ÖZ
İyonosfer tabakası, Küresel Konumlandırma Sistemi (GPS) uydularına ait radyo sinyallerinin frekanslarına bağlı olarak zaman gecikmesine neden olan bir ortamdır. Çoğu iyonosferik çalışma, GPS gözlemlerinden elde edilen toplam elektron içeriği (TEC) değişimleri kullanılarak gerçekleștirilmektedir. Günümüzde iyonosferin fiziksel yapısı ile ilgili çalışmalar, uzay iklim koşullarının tahmini, konumlandırma, navigasyon ve iletişim gibi birçok alanda devam etmektedir. Bu çalışma, iyonosferik TEC'in tahmini için derin öğrenme tabanlı bir model oluşturulması amaçlanmıştır. Bu yöntem için tasarlanan yapay sinir ağı ve ilgili parametreleri, Derin Öğrenme Araç Kutusu kullanılarak MATLABß ortamında hazırlanmıştır. Çalışmada Harran Üniversitesi Kampüs Alanında bulunan HRUH sabit GNSS istasyonuna ait GPS gözlemleri kullanılmıștır. Bu çalışmada, 2019 yılının ilk altı ayı için iyonosferik TEC değişimlerini tahmin etmeyi amaçlayan optimum parametrelerin belirlenmesi araştırılmıştır. Olușturulan modelde yineleme sayısı sabit olarak $(i=100)$ seçilmiștir. Gizli katman sayısının 20 olarak seçildiği parametrelerle minimum karesel ortalama hata $(\mathrm{KOH})$ değeri $\pm 0.287 \mathrm{TECU}$ hesaplanmıştır. 1 gizli katmanda hesaplanan tahmin modelinin $\mathrm{KOH}$ değeri ise \pm 0.472 TECU'dur.
\end{abstract}

\section{Deep learning-based ionospheric TEC forecasting}

\author{
Keywords \\ Deep Learning \\ TEC \\ GPS \\ Ionospheric Delay \\ LSTM
}

\begin{abstract}
The ionosphere layer is an environment that causes a time delay depending on the frequencies of the radio waves of the Global Positioning System (GPS) satellites. Most ionospheric studies are performed using total electron content (TEC) changes obtained from GPS signals. Today, studies on the physical structure of the ionosphere continue in many areas such as the prediction of space weather conditions, positioning, navigation, and communication. This study aims to create a deep learning-based model for the prediction of ionospheric TEC. The artificial neural network and related properties designed for this method have been prepared in the MATLAB® environment using the Deep Learning Toolbox. In this study, HRUH permanent GNSS station which is located in Harran University Campus Area, GPS observations are used. In this study, the determination of the optimum parameters was investigated which aims to forecast ionospheric TEC variations for the first six months of 2019. In the created model, the number of iterations is selected as constant $(i=100)$. The minimum root mean square error (RMSE) value is \pm 0.287 TECU with parameters where the number of hidden layers is selected as 20 . The RMSE value of the forecasting model which is calculated in 1 hidden layer is \pm 0.472 TECU.
\end{abstract}




\section{GíRIş}

Küresel konumlandırma sistemi (GPS) uydu teknolojisine bağlı konumlandırma ve navigasyon sistemidir. GPS; hava, deniz ve kara navigasyonu gibi farklı alanlarda çok yaygın bir biçimde kullanılmakla beraber gündelik yaşam, endüstri, araştırma ve eğitim uygulamalarında da sıkça kullanılmaktadır. Konumlandırma da karşımıza çıkan atmosferik etkilerin büyük bir kısmı GPS sinyalleri üzerindeki iyonosferik etkilerden kaynaklanmaktadır. İyonosferde meydana gelen bozulmalar; özellikle uzay iklim koşullarının meydana getirdiği değişimlerin, radyo iletişim sistemine ve yayılımına etki etmektedir (Tan 2008). Bu nedenle iletişim, navigasyon, radar gibi radyo sinyallerinin iletişimini olumsuz yönde etkileyebilir (Tan ve Ark., 2011). İyonosfer radyo iletişiminde önemli bir rol oynadığından dolayı yapılacak uygulamalar iyonosferik şartlar göz önünde tutularak gerçekleştirilmelidir.

Günümüzde birçok alanda kullanılmaya başlayan yapay sinir ağları bir yapay zeka ürünüdür. Yapay zekanın alt dalı olan derin öğrenme ise bir bilgisayarın ya da bilgisayar destekli bir makinenin, genellikle insana özgü nitelikler, çözüm yolu bulma, anlama, bir mana çıkarma, genelleme ve geçmişteki deneyimlerinden öğrenme gibi yüksek mantık süreçlerine ilişkin görevleri yerine getirme yeteneği olarak bilim dünyasında tanımlanmıștır (Nabiyev 2012). Derin öğrenme, sağlık alanı başta olmak üzere otomotiv, elektronik, enerji, uzay bilimleri, bankacılık, finans ve askeri alanlarda (Kaya ve Ark., 2018), trafik kontrolünde (Tektas ve Ark., 2002), tıp ve sağlık hizmetlerinde veri madenciliği üzerinde (Koyuncugil ve Özgülbaş 2009), İstatistiksel tahmin yöntemlerinde (Emel ve Taşkın 2002; Karahan 2015), meteorolojik yağıș verilerinin tahmininde (Partal ve Ark., 2008), endüstriyel problemlerin çözümünde (Engin ve Döyen 2004), güç sistemlerinde yük akış analizleri (Adepoju ve Ark., 2007), arza ve arazi değerleme uygulamalarında (Tabar and Şişman 2020) gibi pek çok alanlarda etkin rol almaya başlamıştır

Toplam Elektron İçeriği (TEC), GPS uydularından GPS alıcısına gelen sinyal yolu boyunca 1 metrekarelik kesit alanında elde edilen toplam elektron sayısı olarak tanımlanır ve birimi TECU olarak ifade edilir (Şentürk 2020). TEC, serbest elektronlar aracılığıyla düzeltilmiş GPS sinyallerinden elde edilen iyonosferik değişkenlikler hakkında bilgi sağlayan önemli bir parametredir (Schmidt ve Ark., 2008; Chakraborty ve Ark., 2014). Jeomanyetik alan ve güneş aktiviteleri arasındaki karmașık fiziksel etkileşimler, iyonosferik etkilerin modellenmesini ve tahmin edilmesini zorlaştırır (Xu 2007). GPS aracılığıyla yapılan gözlemler, navigasyon ve konumlandırma uygulamalarıyla birlikte iyonosferik uzay iklim koşullarının etkilerinin araştırılmasında da kullanılmaktadır (Hofmann-Wellenhof ve Ark., 2008).

Yapay Sinir ağları (YSA) modelleri GPS ile ölçülen TEC zaman serileri kullanılarak iyonosferik TEC farklılıklarının modellenmesi ve tahmini için kullanılacaktır. Sinir ağları, istatistiksel yöntemlerden daha iyi performans gösterse de uzun yılların TEC örneklerini içeren çok sayıdaki eğitim verilerinin gerekliliği ve eğitim sürecinde sinaptik ağırlıkların belirlenmesindeki karmaşıklık ve kısa süreli TEC tahmini için sinir ağları modelinin uygulanmasını sınırlayan matematiksel arka plan eksikliği belirlenmiștir (Tulunay ve Ark., 2006; Leandro ve Santos 2007). Bu sebepten dolayı tekrarlayan sinir ağları (RNN) derin öğrenmede zaman serileri için tasarlanmıştır. LSTM, zaman serilerini ve uzun menzilli bağımlılıklarını modellemek için tasarlanmış, belirli bir tekrarlayan sinir ağı (RNN) mimarisidir (Hochreiter ve Schmidhuber 1997). TEC değişimlerinden oluşan geçmiş zaman serileri verilerinden, ileriye yönelik GPS-TEC tahminleri LSTM ağ modeli ile yapılabilmektedir. Kısaca ileriye yönelik zaman serileri ve bu seriler arasındaki ilișki bulunabilmektedir. Bu çalışmada TEC zaman serisi tahmini için yukarıda bahsedilen GPS-TEC verilerinden Uzun Kısa Süreli Hafıza (Long Short-Term Memory: LSTM) Tahmini ile oluşturulan modelin performansı araştırılacaktır. Bu amaçla, LSTM ağ modeli, 24. güneş döngüsü sırasında üç yıllık sıralı TEC verileri kullanılarak ardışık yılın ilk yarısına ait TEC tahmininin yapılması için uygulanmiştır.

\section{YÖNTEM}

$\mathrm{Bu}$ çalışmada, HRUH sabit GNSS istasyonundan elde edilen 2016-2019 yılları arasındaki GPS gözlemlerinden TEC değerleri belirlenmiș ve yapay sinir ağı tabanlı derin öğrenme yöntemine göre 2019 yılının ilk yarısındaki 4368 TEC değerinin tahmin edilmesi için bir uygulama gerçekleştirilmiştir.

\subsection{Yapay Sinir Ağları (YSA)}

Yapay Sinir Ağı (YSA) insan beyninin bilişsel öğrenme sürecinin benzetimi ile geliştirilmiş bir yöntemdir (Karahan 2015). YSA insan beyninin öğrenme yapısına iki farklı biçimde benzerlik göstermektedir (Ataseven 2013; Gülpınar 2015; Tabar ve Ark., 2020). Birincisi, YSA'da bilgiler, öğrenme sürecince ağ tarafından elde edilir. İkincisi ise yapay sinir ağındaki sinaptik ağırlıklar olarak bilinen nöronlar arasındaki ilişki bilginin saklanması için kullanır.

Yapay sinir ağları içerisinde oluşturulan modeller; tek/çok katmanlı algılayıcılar ve ileri/geri beslemeli yapay sinir ağları olmak üzere dört farklı kategoride incelenmektedir (Öztürk ve Şahin 2018). Derin öğrenme yöntemi ise bu dört modelin kullanıldığ yapay sinir ağlarının bir alt kümesidir. Derin öğrenme yöntemleri, Evrişimsel (Konvolüsyonel) Sinir Ağları, Tekrarlayan Sinir Ağları (RNN), Uzun Kısa Süreli Hafıza Ağları (LSTM), Sınırlı Boltzman Makineleri (RBM), Derin İnanç Ağları (DBN) ve Derin Oto-Kodlayıcılar (DAE) olmak üzere altı grupta incelenebilir (Şeker ve Ark., 2017). Evrișimsel sinir ağları, çok katmanlı algılayıcıların kullanılarak ileri beslemeli bir yapının oluşturulduğu derin öğrenme yöntemidir (Fukushima 1980).

Evrişimsel sinir ağları; görüntü işlemede (Karpathy ve Fei-Fei 2017), anlamsal ayrıştırmada (Grefenstette ve Ark., 2015), arama sorgusu elde etmede (Shen ve Ark., 2014), cümle modelleme (Kalchbrenner ve Ark., 2014), sinıflandırmada (Kim 2014) ve tahmin problemlerinde (Collobert ve Weston 2008) kullanılmıştır. RNN ise girdiler arasındaki ilişkilerin yönlendirilmiş bir döngü oluşturduğu derin öğrenme türüdür. Bu döngü sayesinde devimsel zamansal davranış sergilemesine imkan 
tanıyan bir ağ durumu oluşturulmuştur. İleri beslemeli sinir ağlarının aksine, RNN'ler kendi giriș hafızasını girdilerin rastgele dizilerini ișlemek için kullanırlar (Mikolov ve Ark., 2010). LSTM, RNN modelinin gelişmiş bir türü olup son zamanlarda derin öğrenme çalışmalarında sıkça kullanılan en önemli yöntemlerinden biri olmuştur. RNN yönteminde girdinin bir önceki bilginin kullanımına bağlı bir yaklaşımı vardır ve girdiler arasındaki boşlukların artması ile RNN modelinin geçmişten gelen bilgileri hafızada tutması ve kullanması zor bir hale gelmektedir (Bengio ve Ark., 1994). Bu problemi çözmek için, uzun vadeli girdilerin ilişkilerini öğrenebilen özel bir RNN türü olan LSTM ağları Hochreiter ve Schmidhuber tarafından literatüre kazandırılmıştır (Hochreiter ve Schmidhuber 1997).

RBM, girdi setleri üzerinde olasılık dağılımını öğrenebilen üretken bir derin öğrenme yöntemidir. RBM'ler, boyut indirgeme (Hinton ve Salakhutdinov 2006), sinıflandirma (Larochelle ve Bengio 2008), işbirlikçi filtreleme (Salakhutdinov ve Ark., 2007), özellik öğrenimi (Coates ve Ark., 2011) ve konu modelleme (Salakhutdinov ve Hinton 2009) gibi farklı konularda kullanılarak başarılı sonuçların alındığı bir yöntemdir. DBN ise RBM'lerin özel bir biçimi olup son gizli katmanında bulunan softmax fonksiyonunu kullanarak sınıflandırma veya denetimsiz bir öğrenme için çok boyutlu mantıksal kümeleme özelliğine sahip yöntemdir (Hinton ve Salakhutdinov 2006). DBN yöntemi, görüntü tanıma ve üretme konularında yaygın olarak kullanılmaktadır (Ranzato ve Ark., 2007).

DAE, denetimsiz öğrenme için kullanılan bir özel derin öğrenme yöntemidir (Liou ve Ark., 2014). Bu yöntem, girdi setlerinin sıkıştırılmış gösteriminden en iyi özelliklerin öğrenilmesini amaçlayan, ileri beslemeli sinir ağlarından oluşur (Krizhevsky ve Hinton 2011). DAE, anormali ve aykırı değer saptanması gibi alanlarda oldukça başarılı sonuçlar vermektedir (Yadav ve Subramanian 2016).

Biyolojik sinir hücresi ile yapay sinir ağı hücresine ait benzerlik şekil 1'de detaylı olarak görülmektedir.

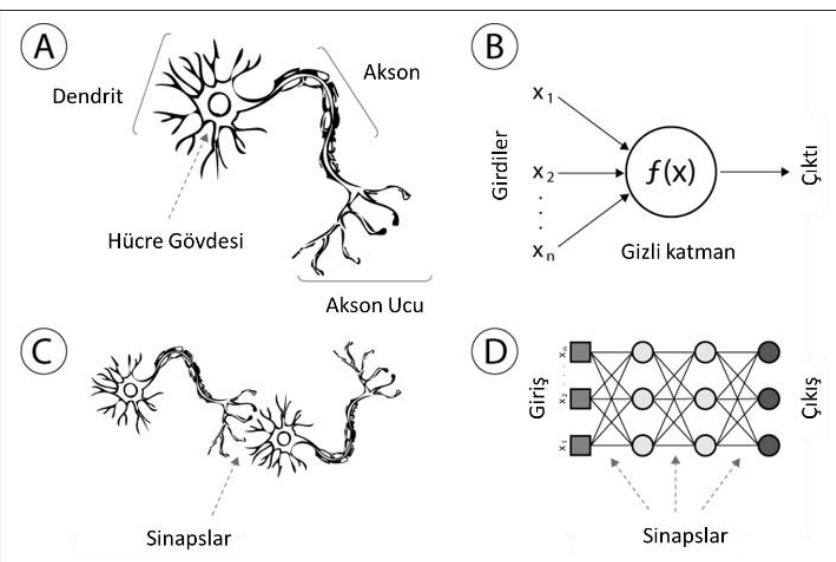

Şekil 1. Biyolojik sinir hücresi ve yapay sinir ağı hücresi (Goncalves ve Ark., 2013'ten değiştirilerek)

Şekil 1'de A, insan sinir sistemine ait nöron; B, yapay sinir ağı nöronu veya gizli katman; $C$, biyolojik sinaps ve D, yapay sinir ağı sinapsları olarak gösterilmektedir.

YSA'nın genel amacı öğrenme sürecidir ve insan beynine benzer șekilde eğitilme ve test etme ile öğrenim gerçekleşir (Karymshakov ve Abdykaparov 2012). YSA; öğrenme, hafızaya alma ve veriler arasındaki ilişkiyi ortaya çıkarma kapasitesine sahiptir (Özkan 2012). İnsan beyninin çalışma prensibini taklit eden YSA; örneklerden öğrenebilme (öğrenme), genelleme yapabilme, eksik bilgi ile çalışabilme, örüntü tamamlama, ilişki kurma (ilişkilendirme), sınıflandırma ve optimizasyon işlemlerinden birini veya birkaçını yapabilme gibi birçok önemli özelliğe sahiptir (Öztemel 2006; Aydemir ve Ark., 2014). YSA matematiksel bir model olmakla birlikte bağlantılı nöronların bulunduğu katmanlardan oluşmaktadır (Keskin Benli ve Güneri Tosunoğlu 2012).

Yapay sinir hücresi veya yapay nöron YSA'nın genel işlemlerinde rol alan temel elemanı veya temel birimidir (Aydemir ve Ark., 2014). Bu birim Şekil 2'de şematik olarak gösterilmiştir.

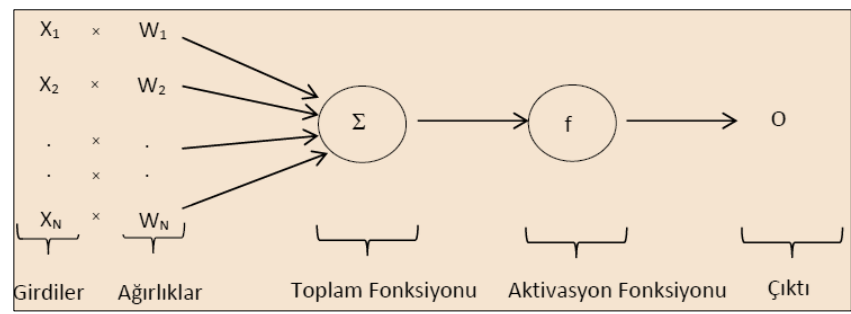

Şekil 2. Yapay sinir ağı hücresi (Nöron)

Şekil 2'de $\mathrm{X}_{1}, \mathrm{X}_{2}, \ldots, \mathrm{X}_{\mathrm{N}}$ girdiler; $\mathrm{W}_{1}, \mathrm{~W}_{2}, \ldots, \mathrm{W}_{\mathrm{N}}$ ağırlıklar; $\Sigma$, toplam fonksiyonu; $f$, aktivasyon fonksiyonu ve $O$ çıktı değerleri olarak gösterilmektedir. Yapay sinir hücrelerinde çıktının elde edilme süreci ağırlıkların girdiler ile çarpılması ve bu çarpımların toplanması (net= $\mathrm{W}_{1} \mathrm{X}_{1}+\mathrm{W}_{2} \mathrm{X}_{2}+\ldots+\mathrm{W}_{\mathrm{N}} \mathrm{X}_{\mathrm{N}}$ ) sonucu elde edilen net değişkeni ile başlar. Daha sonra net değişkeni aktivasyon fonksiyonundan geçirilerek çıktı değerleri $O=f(n e t)$ eşitliğinden elde edilir (Tüzüntürk ve Ark., 2016).

\subsection{Uzun-Kısa Dönemli Hafıza Modeli}

Toplam Elektron İçeriği (TEC) zaman serilerinin tahmini için önerilen Uzun-Kısa Dönemli Hafıza Modeli (Long Short-Term Memory: LSTM) ağ mimarisinde; girdi katmanları, LSTM katmanları, gizli katmanlar ve çıktı katmanları olmak üzere 4 katmanlı bir yapıdan oluşmaktadır (Şekil 3). Bu yapıdaki girdi katmanının her bir elemanı TEC değerlerinden elde edilen vektörlerdir.

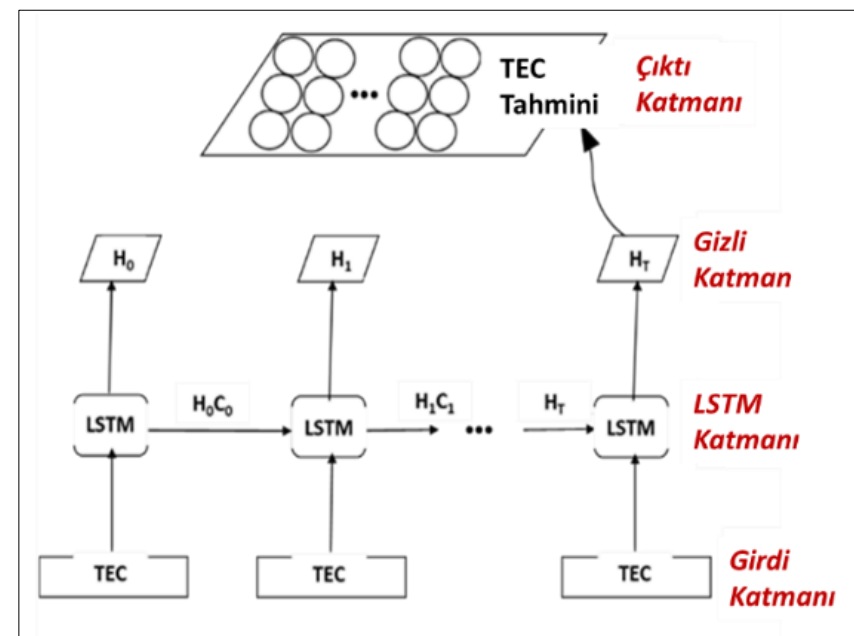

Şekil 3. LSTM ağ mimarisi 
Şekil 3'te görüldüğü gibi, girdi katmanının her bir öğesi, TEC değerlerinden elde edilen vektörler olarak tanımlanmıștır. Bir LSTM katmanının giriș sırasını $\left[\mathrm{x}_{\mathrm{t}}=\right.$ $\left.\left(\mathrm{x}_{1}, \mathrm{x}_{2}, \mathrm{x}_{3}, \ldots, \mathrm{x}_{\mathrm{n}}\right)\right]$ gizli bir çıktı değeri vektörünün $\left[\mathrm{h}_{\mathrm{t}}=\left(\mathrm{h}_{1}\right.\right.$, $\left.\left.h_{2}, h_{3}, \ldots, h_{n}\right)\right]$ sırasına göre eşlenmesi burada gerçekleșir. $\mathrm{Bu}$ işlemlerin tekrar süreci aşağıdaki eşitliklere göre sürdürülmektedir.

$$
\begin{aligned}
& \mathrm{i}_{\mathrm{t}}=\sigma\left(\mathrm{W}_{\mathrm{ix}} \mathrm{Xt}_{\mathrm{t}}+\mathrm{W}_{\mathrm{ihh}} \mathrm{h}_{\mathrm{t}-1}+\mathrm{b}_{\mathrm{i}}\right) \\
& f_{\mathrm{t}}=\sigma\left(\mathrm{W}_{\mathrm{fx}} \mathrm{X}_{\mathrm{t}}+\mathrm{W}_{\mathrm{fh}} \mathrm{h}_{\mathrm{t}-1}+\mathrm{b}_{\mathrm{f}}\right) \\
& \mathrm{o}_{\mathrm{t}}=\sigma\left(\mathrm{W}_{\mathrm{ox}} \mathrm{X}_{\mathrm{t}}+\mathrm{W}_{\mathrm{oh}} \mathrm{h}_{\mathrm{t}-1}+\mathrm{b}_{\mathrm{o}}\right) \\
& \mathrm{c}_{\mathrm{t}}=\mathrm{f}_{\mathrm{t}} * \mathrm{c}_{\mathrm{t}-1}+\mathrm{i}_{\mathrm{t}}{ }^{*} \tanh \left(\mathrm{W}_{\mathrm{ox}} \mathrm{X}_{\mathrm{t}}+\mathrm{W}_{\mathrm{ch}} \mathrm{h}_{\mathrm{t}-1}+\mathrm{b}_{\mathrm{c}}\right) \\
& \mathrm{h}_{\mathrm{t}}=\mathrm{O}_{\mathrm{t}} * \tanh \left(\mathrm{c}_{\mathrm{t}}\right)
\end{aligned}
$$

Eşitliklerdeki i, her gizli birime girişin ne kadarının iç durum vektörüne $\left(c_{t}\right)$ yazıldığını kontrol eden giriş (input) kapısındaki değerdir. W, sürece dahil olan ağırlıkları (weight) ve $f$, bir önceki iç durumun ( $\mathrm{c}_{\mathrm{t}-1}$ ) ne kadarının korunduğunu belirleyen hafıza boşaltım kapısını göstermektedir. Yazma ve boșaltım kapılarından olușan kombinasyon, ağın her adımda hangi bilgilerin saklanması ve yeni durum için hangi yeni değerlerin, mevcut değerin üzerine yazılması gerektiği durumun kontrol edilmesini sağlamaktadır. 0, çıkış (output) kapısıdır ve her bir birimin güncellenmesini koruyacak süreci kontrol etmektedir ve LSTM hücresinin ilgili olmayan bilgilerinin saklanmasında görev almaktadır. $\mathrm{ct}_{\mathrm{t}}$ zaman serisi verilerinin uzun bağımlılıklarını öğrenen hücredir. Son gizli durum $h$, zaman serisi verilerinin tahmini değerlerini temsil etmektedir (Sun ve Ark., 2017). LSTM bloğuna ait işleyişin açıklandığı şema şekil 4'te verilmiştir.

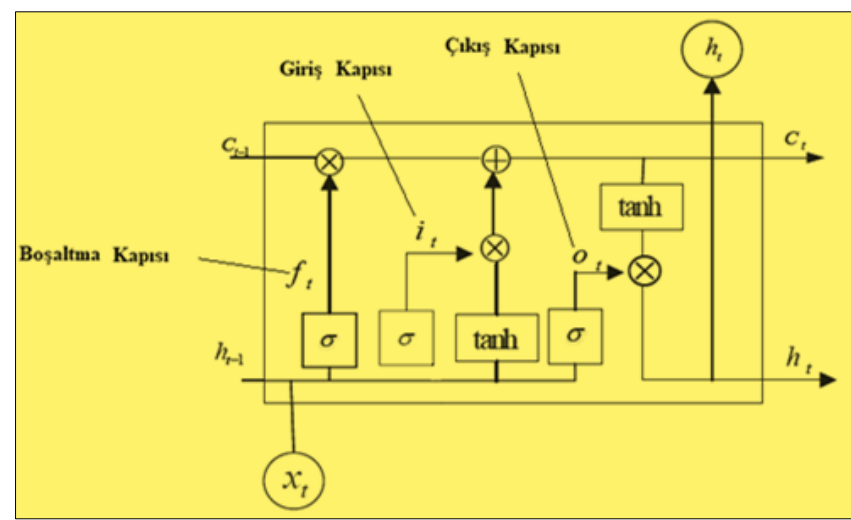

Şekil 4. LSTM bloğuna ait çalışma süreci

Şekil 4'te görüldüğü gibi LSTM bloğu sigmoid $(\sigma)$ ve tanh gibi iki etkileştirme fonksiyonuna sahiptir. Sigmoid fonksiyonu, gerekli bilgilerin güncellenmesine karar verir ve yalnız başına sadece belleğe çevrim sürecindeki sonuç bilgileri ekler ancak belleği boşaltamaz. tanh fonksiyonu ise YSA üzerinden geçen değerleri düzenler ve hücre yolunun hafızayı boşaltmasında rol oynar (Zhang ve Ark., 2017).

\subsection{GPS Gözlemlerinden TEC Değişimlerinin Elde Edilmesi}

İyonosferik TEC değişimleri GPS sinyallerinin kod (P) veya taşıyıcı faz ( $\Phi)$ ölçülerinin geometriden bağımsız kombinasyonu kullanılarak belirlenebilir (Inyurt ve Ark., 2017; Schmidt ve Ark., 2008). TEC değerleri TECU biriminde, GPS uyduları ile yeryüzündeki GPS alıcısı arasında ortaya çıkan sinyal yolu boyunca atmosferin 1 metrekare taban alanına sahip silindir ile iyonosfer tabakasının belirli bir yüksekliğinde bu silindirin ile oluşan arakesitinde ölçülen elektron miktarıdır. 1 TECU=1016 elektron/ $\mathrm{m}^{2}$ 'dir. Her bir u GPS alıcısı ve m GPS uydusu arasındaki eğri sinyal yolu boyunca belirlenen Eğik Toplam Elektron İçeriği (STEC) değeri, uydu ve alıcı donanımlarına bağlı $f_{1}$ ve $f_{2}$ frekanslarındaki sinyal gecikmelerinin diferansiyel kod farklarını (DCBs) GPS gözlemlerinden elimine ederek belirlenebilmektedir. Elde edilen STEC değerleri iyonosferik ince tabaka modeline göre eşitlik 6'daki M(z) izdüşüm fonksiyonu kullanılarak Düşey Toplam Elektron İçeriği (VTEC) değerine dönüştürülür (Şentürk ve Çepni 2018).

$$
M(z)=1 / \cos z^{\prime}
$$

Burada z', uydu ile alıcı arasındaki sinyal yolu boyunca ince kabuk modeline göre tanımlanan iyonosfer tabakasının delindiği noktanın (IPP) zenit açısı olarak kullanılmaktadır. VTEC değerleri eşitlik 7'de verilen denklem kullanılarak GPS alıcısı ile her bir GPS uydusu arasındaki sinyal yolu boyunca elde edilir (İnyurt ve Ark., 2020).

$$
\mathrm{VTEC}=\mathrm{STEC} * \mathrm{M}(\mathrm{z})
$$

$\mathrm{Bu}$ çalışmada, kullanılan VTEC değişimleri birçok çalışmada güvenilirliği kanıtlanmış Seemala (2011) tarafından geliştirilen yazılım ile bir saatlik zamansal çözünürlükte elde edilmiştir (Adewale ve Oyeyemi 2018; Tariq ve Ark., 2019; Chekole ve Giday 2020). Bu çalışmanın tamamında bahsi geçen TEC değişimleri, STEC değișimlerinden hesaplanan VTEC değişimleri anlaşılmalıdır.

\section{BULGULAR}

Bu çalışmada, HRUH sabit GNSS istasyonundan elde edilen 2016-2019 yılları arasındaki toplam 3,5 yıllık GPS gözlemleri kullanılmıştır. GPS gözlemlerinden elde edilen TEC değerleri, 2019 yılının ilk yarısındaki 4368 TEC değerinin tahmin edilmesi için YSA tabanlı derin öğrenme yöntemine ait bir uygulama kullanılarak yapılmıştır. Hagan ve Ark. (1995) yapay sinir ağlarının eğitim ve test verilerine ait oranı en az \%80'e \%20 oranında önermiştir. Bu uygulamada eğitim verileri tüm verilerin \%86'sını, test verileri ise \%14'ünü oluşturmaktadır. GPS gözlemlerinin RINEX formatındaki verileri kullanılarak istasyon üstü iyonosferik TEC değişimleri Seemala (2011) tarafından geliştirilen GPSTEC analiz yazılımı kullanılarak TECU biriminde elde edilmiştir. Şekil 5'te HRUH GNSS istasyonuna ait elde edilen 3,5 yllık iyonosferik TEC değişimleri verilmiştir.

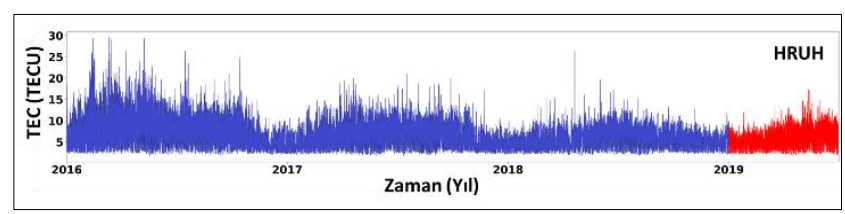

Şekil 5. Çalışmada kullanılan HRUH sabit istasyonuna ait TEC değișimleri 
Şekil 5'de, derin öğrenme yöntemi modeli içinde kurulan LSTM ağında kullanılacak 3 yıllık (2016, 2017 ve 2018) TEC değișimlerine ait eğitim verisi mavi renkte, tahmin gerçekleștirildikten sonra da verilerin testi için kullanılacak TEC değişimleri kırmızı renkte görülmektedir. HRUH istasyonu için 1 saatlik zamansal çözünürlükle elde edilen veri sayısı 30672 değerden oluşmaktadır. MATLAB ortamında derin öğrenme yöntemine göre 3 yıllık veriyi eğitmek için; derin öğrenme modelinin başlangıç öğrenme hızı, gizli katman sayısı ve yineleme sayısı gibi ana parametreler belirlenmiștir. Bilgiler sigmoid fonksiyonu ile güncellenmiş ve çıktı verilerinin ağın evrişimi için önceki verilerle ilişkilendirilmesi sağlanmıştır. Daha sonra belirlenen parametrelere göre ağın eğitimi gerçekleştirilmiş ve test verilerinin standardizasyonu yapılmıştır. 2019 yılının ilk altı ayı için iyonosferik TEC değişimleri ve tahmin değerleri elde edilmiş ve karesel ortalama hatalar $(\mathrm{KOH})$ hesaplanmıştır. Örnek olarak 2019 yılının ilk 50 gününe ait bir saat çözünürlükle tahmin edilen TEC değișimlerinin test verileriyle karşılaştırılması ve aralarındaki $\mathrm{KOH}$ değerlerine ait sonuç görseli şekil 6'da gösterilmektedir.

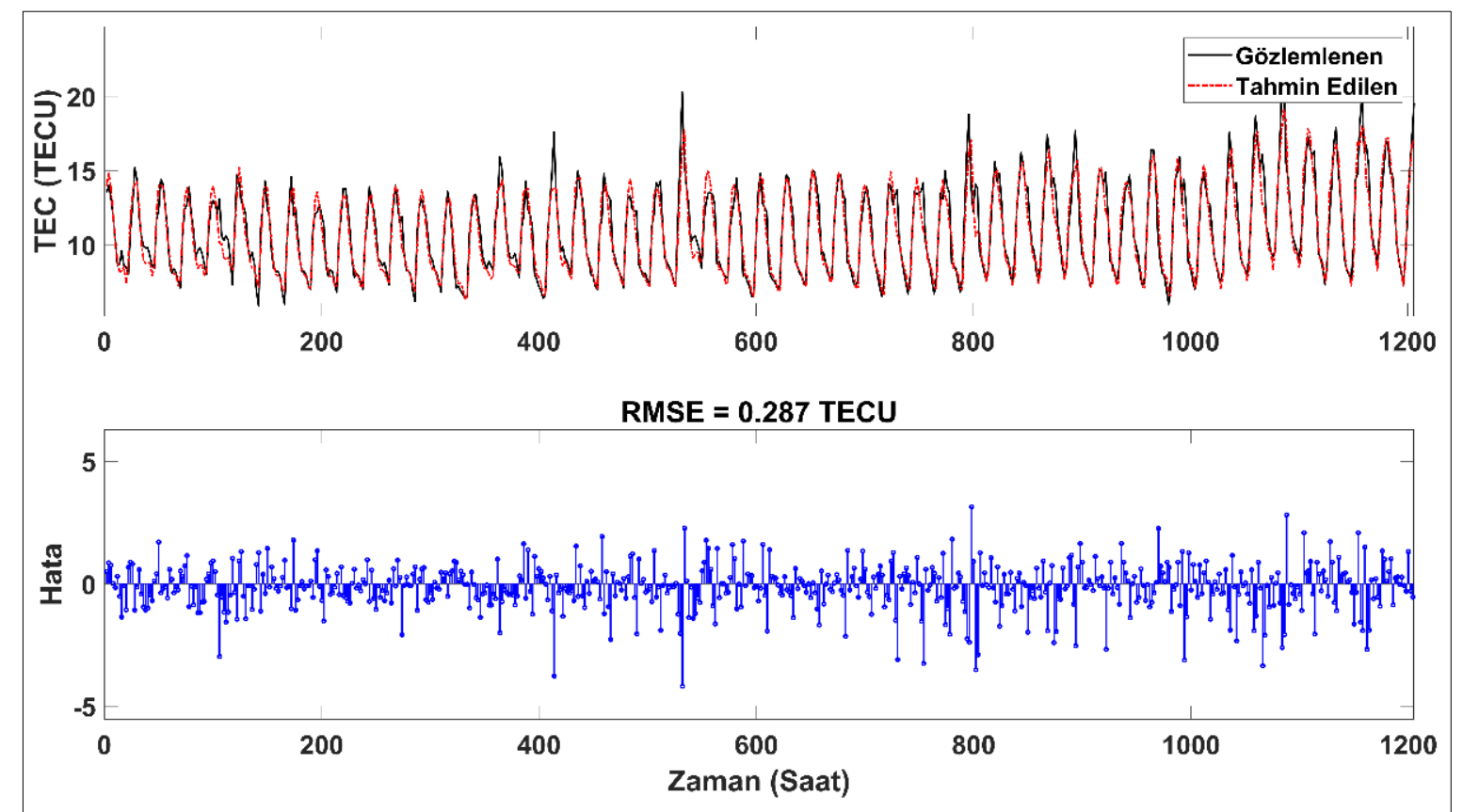

Şekil 6. 2019 yılının ilk 50 gününe ait TEC tahminleri

LSTM ağ mimarisinde yapılan değerlendirmelerde gizli katman sayısı 50 gizli katman sayısına kadar sırasıyla artırılarak $\mathrm{KOH}$ değerlerinin değişimi gözlemlenmiş ve yineleme sayısı ise sabit 100 olarak seçilmiştir. Denemeler sonucunda elde edilen tahmin değerleri ile test değerlerinden hesaplanan TECU birimindeki $\mathrm{KOH}$ değerleri Şekil 7 ve Tablo 1'de gösterilmiştir.

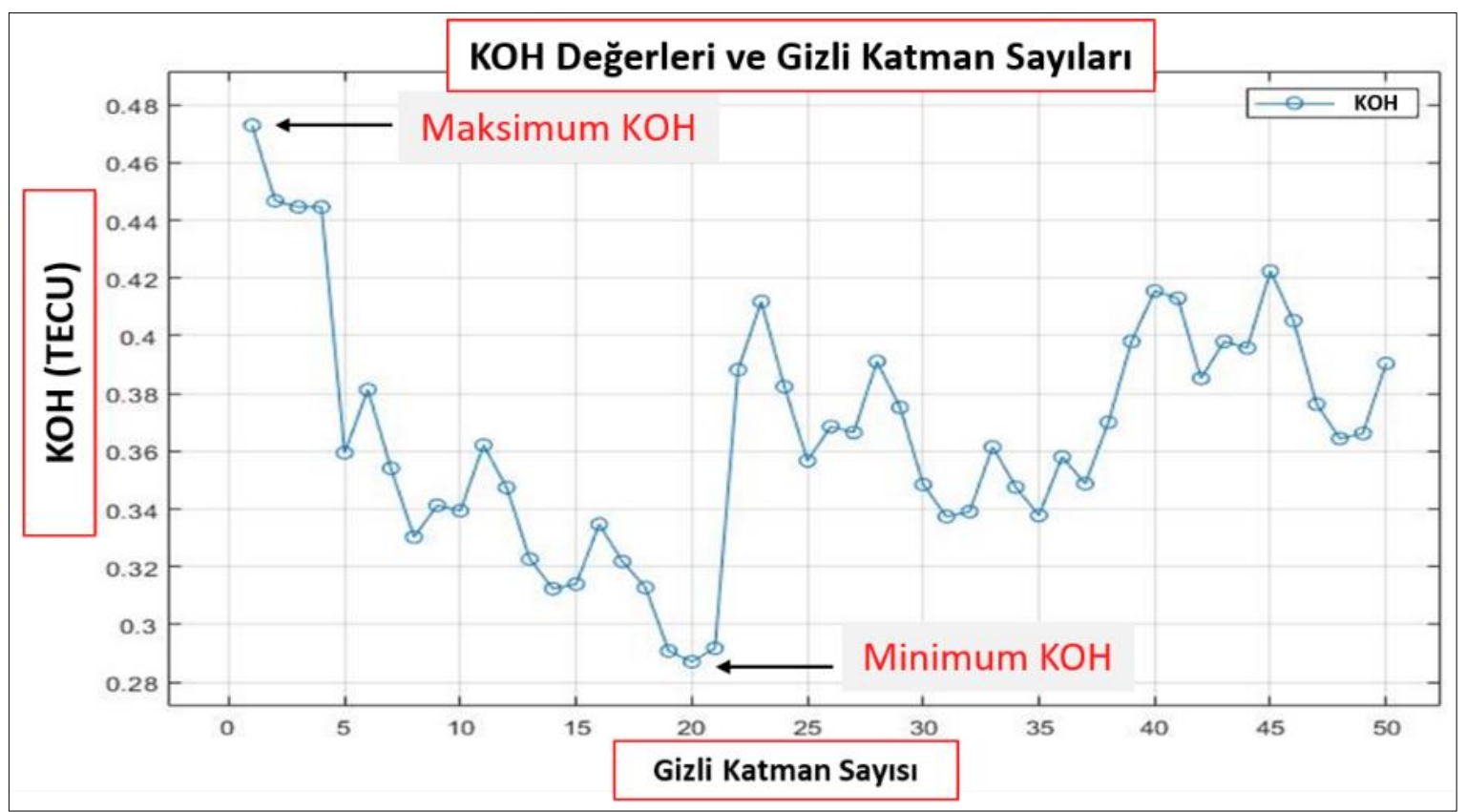

Şekil 7. Gizli katman sayısı değiștirilerek hesaplanan KOH değerleri 
Şekil 7'de görüldüğü gibi gizli katman sayısı arttıkça KOH değerlerinde azalma olduğu ancak 20. gizli katman değerinden sonra sürecin doğrusal bir şekilde gerçekleşmediği gözlemlenmiştir. Gizli katman sayısı 20 seçildiğinde minimum $\mathrm{KOH}$ değeri $\pm 0.287 \mathrm{TECU}$ olarak belirlenmiş olup, gizli katman sayısının 1 olduğu durumda ise maksimum $\mathrm{KOH}$ değeri \pm 0.472 TECU olarak hesaplanmıştır.

Tablo 1. LSTM ağı için seçilen parametrelere göre hesaplanan KOH değerleri

\begin{tabular}{cc|cc}
\hline $\begin{array}{c}\text { Gizli } \\
\text { Katman }\end{array}$ & $\begin{array}{c}\text { KOH } \\
\text { (TECU) }\end{array}$ & $\begin{array}{c}\text { Gizli } \\
\text { Katman }\end{array}$ & $\begin{array}{c}\text { KOH } \\
\text { (TECU) }\end{array}$ \\
\hline $\mathbf{1}$ & $\mathbf{0 . 4 7 2}$ & 26 & 0.368 \\
2 & 0.446 & 27 & 0.366 \\
3 & 0.444 & 28 & 0.391 \\
4 & 0.444 & 29 & 0.375 \\
5 & 0.359 & 30 & 0.348 \\
6 & 0.381 & 31 & 0.337 \\
7 & 0.354 & 32 & 0.339 \\
8 & 0.330 & 33 & 0.361 \\
9 & 0.341 & 34 & 0.347 \\
10 & 0.339 & 35 & 0.337 \\
11 & 0.362 & 36 & 0.358 \\
12 & 0.347 & 37 & 0.348 \\
13 & 0.322 & 38 & 0.370 \\
14 & 0.312 & 39 & 0.398 \\
15 & 0.313 & 40 & 0.415 \\
16 & 0.334 & 41 & 0.412 \\
17 & 0.321 & 42 & 0.385 \\
18 & 0.312 & 43 & 0.398 \\
19 & 0.290 & 44 & 0.395 \\
$\mathbf{2 0}$ & $\mathbf{0 . 2 8 7}$ & 45 & 0.422 \\
21 & 0.291 & 46 & 0.405 \\
22 & 0.388 & 47 & 0.376 \\
23 & 0.411 & 48 & 0.364 \\
24 & 0.382 & 49 & 0.366 \\
25 & 0.356 & 50 & 0.390 \\
\hline & & &
\end{tabular}

Tablo 1'de gizli katman sayısına bağlı olarak 100 yinelemeli denemelere ait $\mathrm{KOH}$ sonuçları görülmektedir. Hesaplamalar sonucunda en düşük $\mathrm{KOH}$ değeri 20. gizli katmanda ve en yüksek $\mathrm{KOH}$ değeri ise 1. gizli katmanda ortaya çıktığı görülmektedir.

\section{SONUÇLAR}

Çalışmada, HRUH sabit GNSS istasyonuna ait TEC değișimlerinin 2019 yllının ilk 6 ayına ait TEC tahminleri MATLAB ortamında hazırlanan derin öğrenme yönteminde olușturulan LSTM mimarisine göre araştırılmıştır. HRUH GNSS istasyonunun 2016-2018 yılları arasındaki GPS gözlemlerinden elde edilen TEC değerleri kullanılarak 2019 yılının ilk yarısındaki 4368 TEC değerinin tahmin edilmesi için örnek bir uygulama yapılmıştır. GPS gözlemlerinin RINEX formatındaki verileri kullanılarak istasyon üstü iyonosferik TEC değişimleri Seemala (2011) tarafından geliștirilen GPSTEC analiz yazılımı kullanılarak TECU biriminde elde edilmiştir. Bu çalışmada hatayı geriye yayma tekniği olan momentumlu stokastik gradyan iniși (SGDM) optimizasyon algoritması kullanılmıştır. Modeldeki TEC değişimlerine ait zaman serisi verileri bir saat çözünürlüklü elde edilen 3,5 yıllık TEC değişimlerinden oluşmaktadır. TEC değişimlerine ait 3 yıllık veri LSTM mimarisi içerisinde oluşturulan modele göre eğitim verisi, geriye kalan veriler ise test verisi olarak kullanılmıștır.

$\mathrm{Bu}$ çalışmada, önerilen LSTM modelinde TEC değişimlerinin 2019 yılının ilk altı aylık verilerinin tahminine yönelik değerlendirilmiștir. LSTM modelinin performansı GPS-TEC verileriyle incelenmiş karesel ortalama hata $(\mathrm{KOH})$ ve gizli katman sayısı parametreleri kıyaslanmıştır. Hesaplamalar sonucunda en düşük $\mathrm{KOH}$ değeri 20. gizli katmanda ve en yüksek $\mathrm{KOH}$ değeri ise 1 . gizli katmanda görülmektedir. Gizli katman sayısının 20 olarak seçildiği parametrelerle minimum $\mathrm{KOH}$ değeri \pm 0.287 TECU, 1 gizli katman seçilerek işletilen modelde KOH değeri \pm 0.472 TECU olarak hesaplanmıștır. Gizli katman sayısının artırılmasına bağlı olarak hesaplanacak KOH değerleri arasında doğrusal bir değişimin olmadığı 50 gizli katmanlı modelden hesaplanan $\mathrm{KOH}$ değerinin \pm 0.390 TECU olarak belirlenmesiyle ortaya çıarılmıştır. 23. gizli katmanda ortaya çıkan KOH değerinin $( \pm 0.411$ TECU) sıçrama yapmasının sebebi ise oluşturulan LSTM mimarisinin 20. gizli katmanından sonraki gizli katmanlarda boş nörona denk gelen verilerden kaynaklı olabileceği söylenebilir.

Derin öğrenme insan beyninin çalışma yapısını taklit ederek mevcut verileri analiz edip, bu verilerden farklı öğrenme algoritmaları ile yeni bilgiler üreten bilgi ișlem teknolojisi olmakla beraber kullanıldığı alanlarda hem avantajları hem de dezavantajları bulunmaktadır. Donanıma bağlı olması, ağın davranışlarının açıklanamaması, yapılacak çözümler için uygun ağ yapısını belirleme için deneme yanılma yönteminin yapılması, ağın eğitilme sürecinin bilinmemesi gibi faktörler derin öğrenmede karşılaşılan bazı problemlerdir. Bu problemlerin aksine, eksik bilgi ile çalışabilmesi, hata toleransına sahip olması, ürettiği bilgileri kendi ağında saklayabilmesi, birden fazla iși yapacak sayısal güce sahip olması derin öğrenmenin son zamanlarda popülerliğini artırmaktadır.

MATLAB $®$ ortamında derlenmiş Derin Öğrenme Araç Kutusunu kullanabilmek için bilgisayar donanımı (işlemci, ekran kartı, hafıza kartı vs.) performansının yüksek olması gerekmektedir. Ayrıca seçilen ağın çözüm yöntemi, zaman serisi verilerini daha iyi temsil edecek şekilde seçilmelidir.

Gelecekte yapılacak çalışmalar dahilinde düşük sayıda TEC verisi kullanılarak yüksek doğrulukta TEC tahmini çalışmalarına yönelik uygulamaların yapılması düşünülmektedir.

\section{ARAŞTIRMACILARIN KATKI ORANI}

İsmail Demiryege: Literatür taraması, Modelleme, Makale yazma; Mustafa Ulukavak: Veri Toplama, Makale yazma, Düzenleme, Şekil Düzenlemeleri

\section{ÇATIŞMA BEYANI}

Herhangi bir çıkar çatışması bulunmamaktadır. 


\section{KAYNAKÇA}

Adepoju G A, Ogunjuyigbe S O A, Alawode K O (2007). Application of Neural Network to Load Forecasting in Nigerian Electrical Power System. Pacific J Sci Technol

Adewale A, Oyeyemi E (2018). Estimation of GPS-TEC using different techniques and comparison with values from IRI-2012, NeQuick-2 and IRI-Plas 2015 models during geomagnetic storms. In: 42nd COSPAR Scientific Assembly. p C1.1-123-18

Ataseven B (2013). YAPAY SINIIR AĞLARI İLE ÖNGÖRÜ MODELLEMESİ. Öneri Derg 10:101-115

Aydemir E, Karaatlı M, Yılmaz G, Aksoy S (2014). 112 Acil Çağrı Merkezine Gelen Çağrı Saylarını Belirleyebilmek için Bir Yapay Sinir Ağları Tahminleme Modeli Geliştirilmesi. Pamukkale Üniversitesi Mühendislik Bilim Derg 20:145-149

Bengio Y, Simard P, Frasconi P (1994). Learning LongTerm Dependencies with Gradient Descent is Difficult. IEEE Trans Neural Networks 5:157-166. doi: $10.1109 / 72.279181$

Chakraborty M, Kumar S, De BK, Guha A (2014). Latitudinal characteristics of GPS derived ionospheric TEC: a comparative study with IRI 2012 model. Ann Geophys 57:. doi: 10.4401/ag-6438

Chekole D A, Giday N M (2020). Evaluation of ionospheric and solar proxy indices for IRI-Plas 2017 model over the East African equatorial region during solar cycle 24. Adv Sp Res 66:604-611. doi: 10.1016/j.asr.2020.04.029

Coates A, Lee H, Ng A Y (2011). An analysis of single-layer networks in unsupervised feature learning. J Mach Learn Res 15:215-223

Collobert R, Weston J (2008). A unified architecture for natural language processing. In: Proceedings of the 25th International Conference on Machine Learning. pp 160-167

Emel GG, Taşkın Ç (2002). Genetik Algoritmalar ve Uygulama Alanları. Uludağ Üniversitesi İktisadi ve İdari Bilim Fakültesi Derg 21:129-152

Engin 0, Döyen A (2004). Artificial immune systems and applications in industrial problems. Gazi Univ J Sci 17:71-84

Fukushima K (1980). Neocognitron: A self-organizing neural network model for a mechanism of pattern recognition unaffected by shift in position. Biol Cybern 36:193-202. doi: 10.1007/BF00344251

Goncalves V, Maria K, da Silv ABF (2013). Applications of Artificial Neural Networks in Chemical Problems. In: Suzuki K (ed) Artificial Neural Networks Architectures and Applications. IntechOpen, Rijeka

Grefenstette E, Blunsom P, de Freitas N, Hermann KM (2015). A Deep Architecture for Semantic Parsing. 22-27. doi: 10.3115/v1/w14-2405

Gülpınar V (2015). Yapay Sinir Ağları ve Sosyal Ağ Analizi Yardımı ile Türk Telekomünikasyon Piyasasında Müşteri Kaybı Analizi. Marmara Üniversitesi İktisadi ve İdari Bilim Derg 34:331-350

Hagan M T, Demuth H B, Beale M H (1995). Neural Network Design. Bost Massachusetts PWS 2:734. doi: 10.1007/1-84628-303-5

Hinton G E, Salakhutdinov R R (2006). Reducing the dimensionality of data with neural networks. Science
(80- ) 313:504-507. doi: 10.1126/science.1127647

Hochreiter S, Schmidhuber J (1997). Long Short-Term Memory. Neural Comput 9:1735-1780. doi: 10.1162/neco.1997.9.8.1735

Hofmann-Wellenhof B, Lichtenegger H, Wasle E (2008). GNSS - Global Navigation Satellite Systems, 1st edn. Springer-Verlag Wien, Wien

İnyurt S, Mekik Ç, Yıldırım Ö (2020). Deprem Kaynaklı Olabilecek İyonosferik Değişimlerin Belirlenmesi üzerine yeni bir yaklaşım geliştirilmesi. Geomatik 5:127-133. doi: 10.29128/geomatik.592477

Inyurt S, Yildirim 0, Mekik C (2017). Comparison between IRI-2012 and GPS-TEC observations over the western Black Sea. Ann Geophys. doi: 10.5194/angeo-35-817-2017

Kalchbrenner N, Grefenstette E, Blunsom P (2014). A convolutional neural network for modelling sentences. 52nd Annu Meet Assoc Comput Linguist ACL 2014 - Proc Conf 1:655-665. doi: 10.3115/v1/p14-1062

Karahan M (2015). Turizm Talebinin Yapay Sinir Ağaları Yöntemiyle Tahmin Edilmesi. Süleyman Demirel Üniversitesi İktisadi ve İdari Bilim Fakültesi Derg 20:195-209

Karpathy A, Fei-Fei L (2017). Deep Visual-Semantic Alignments for Generating Image Descriptions. IEEE Trans Pattern Anal Mach Intell 39:664-676

Karymshakov K, Abdykaparov Y (2012). Forecasting stock index movement with artificial neural networks: The case of Istanbul Stock Exchange. Trak Univ J Soc Sci 14:231-242

Kaya Ü, Oğuz Y, Şenol Ü (2018). An Assessment of Energy Production Capacity of Amasra Town Using Artificial An Assessment of Energy Production Capacity of Amasra Town Using Artificial Neural Networks. Turkish J Electromechanics Energy 3:22-26

Keskin Benli Y, Güneri Tosunoğlu N (2012). Morgan Stanley Capital International Türkiye Endeksinin Yapay Sinir Ağları ile Öngörüsü. Ege Akad Bakis (Ege Acad Rev 12:541-541. doi: 10.21121/eab.2012419515

Kim Y (2014). Convolutional neural networks for sentence classification. EMNLP 2014 - 2014 Conf Empir Methods Nat Lang Process Proc Conf 17461751. doi: $10.3115 / v 1 / d 14-1181$

Koyuncugil A, Özgülbaş N (2009). Veri Madenciliği: Tıp ve Sağlık Hizmetlerinde Kullanımı ve Uygulamaları. Int J Informatics Technol 2:. doi: 10.17671/btd.01471

Krizhevsky A, Hinton GE (2011). Using very deep autoencoders for content-based image retrieval. In: ESANN 2011 - 19th European Symposium on Artificial Neural Networks. pp 489-494

Larochelle H, Bengio Y (2008). Classification using discriminative restricted boltzmann machines. In: Proceedings of the 25th International Conference on Machine Learning. pp 536-543

Leandro RF, Santos MC (2007). A neural network approach for regional vertical total electron content modelling. Stud Geophys Geod 51:279-292. doi: 10.1007/s11200-007-0015-6

Liou CY, Cheng WC, Liou JW, Liou DR (2014). Autoencoder for words. Neurocomputing 139:84-96. doi: 10.1016/j.neucom.2013.09.055 
Mikolov T, Karafiát M, Burget L (2010). Recurrent neural network based language model. In: Proceedings of the 11th Annual Conference of the International Speech Communication Association, INTERSPEECH 2010. pp 1045-1048

Nabiyev V (2012). Yapay Zeka İnsan - Bilgisayar Etkileșimi. Seçkin Yayıncılık, Ankara

Özkan F (2012). Döviz Kuru Tahmininde Parasal Model ve Yapay Sinir Ağları Karşılaștırması. A Comp Monet Model Artif Neural Networks Exch Rate Forecast 3:27-29

Öztemel E (2006). Yapay Sinir Ağları. İstanbul

Öztürk K, Şahin ME (2018). Yapay Sinir Ağları ve Yapay Zekâ'ya Genel Bir Bakış. Tak Vekayi 6:25-36

Partal T, Kahya E, Cığızoğlu K (2008). Yağıș verilerinin yapay sinir ağları ve dalgacık dönüşümü yöntemleri ile tahmini. İTÜ Dergisi, Seri D Mühendislik 7:73-85

Ranzato M, Huang FJ, Boureau YL, LeCun Y (2007). Unsupervised learning of invariant feature hierarchies with applications to object recognition. In: Proceedings of the IEEE Computer Society Conference on Computer Vision and Pattern Recognition. pp 1-8

Salakhutdinov R, Hinton G (2009). Replicated softmax: An undirected topic model. In: Advances in Neural Information Processing Systems 22 - Proceedings of the 2009 Conference. pp 1607-1614

Salakhutdinov R, Mnih A, Hinton G (2007). Restricted Boltzmann machines for collaborative filtering. In: ACM International Conference Proceeding Series. pp 791-798

Schmidt M, Bilitza D, Shum CK, Zeilhofer C (2008). Regional 4-D modeling of the ionospheric electron density. Adv Sp Res 42:782-790. doi: 10.1016/j.asr.2007.02.050

Seemala GK (2011). GPS-TEC analysis application read me

Şeker A, Diri B, Balık HH (2017). Derin Öğrenme Yöntemleri Ve Uygulamaları Hakkında Bïr İnceleme. Gazi Mühendislik Bilim Derg 3:47-64

Şentürk E (2020). Investigation of global ionospheric response of the severe geomagnetic storm on June 2223, 2015 by GNSS-based TEC observations. Astrophys Space Sci 365:110. doi: 10.1007/s10509-020-03828$\mathrm{z}$

Şentürk E, Çepni MS (2018). A statistical analysis of seismo-ionospheric TEC anomalies before $63 \mathrm{M} \mathrm{w} \geq$ 5.0 earthquakes in Turkey during 2003-2016. Acta Geophys 66:1495-1507. doi: 10.1007/s11600-0180214-2

Shen Y, He X, Gao J, et al (2014). Learning semantic representations using convolutional neural networks for web search. In: WWW 2014 Companion -
Proceedings of the 23rd International Conference on World Wide Web. pp 373-374

Sun W, Xu L, Huang X, et al (2017). Forecasting of ionospheric vertical total electron content (TEC) using LSTM networks. In: Proceedings of 2017 International Conference on Machine Learning and Cybernetics, ICMLC 2017. pp 340-344

Tabar ME, Başara A C, Şişman Y (2020). A House Valuation with Multiple Regression Analysis and Artificial Neural Networks. In: Yakar M (ed) Intercontinental Geoinformation Days. Mersin

Tabar ME, Şişman Y (2020). Bulanık Mantık ile Arsa Değerleme Modelinin Oluşturulması. Türkiye Arazi Yönetimi Derg 2:28-24

Tan S-S (2008). Development and thought of compass navigation satellite system. Yuhang Xuebao/Journal Astronaut 29:391-396

Tan S, Zhou B, Guo S, Liu Z (2011). Research on COMPASS navigation signals of China. Zhongguo Kongjian Kexue Jishu/Chinese Sp Sci Technol 31:9-14+29. doi: 10.3780/j.issn.1000-758X.2011.04.002

Tariq M A, Shah M, Ulukavak M, Iqbal T (2019). Comparison of TEC from GPS and IRI-2016 model over different regions of Pakistan during 2015-2017. Adv Sp Res 64:707-718. doi: https://doi.org/10.1016/j.asr.2019.05.019

Tektas M, Akbaş A, Topuz V (2002). Yapay Zeka Tekniklerinin Trafik Kontrolünde Kullanılması Üzerine Bir İnceleme. In: 1. Uluslararası Trafik ve Yol Güvenliği Kongresi. Gazi Üniversitesi, Ankara, pp 551-559

Tulunay E, Senalp ET, Radicella SM, Tulunay Y (2006). Forecasting total electron content maps by neural network technique. Radio Sci 41:. doi: 10.1029/2005RS003285

Tüzüntürk S, Sert Eteman F, Sezen K (2016). YAPAY SINIR AĞI YÖNTEMI İLE DAMACANA SU SATIŞ MIKTARLARININ TAHMINI ESTIMATION OF THE SALES AMOUNTS OF THE DISPENSER SIZE WATER WITH ARTIFICIAL NEURAL NETWORK METHOD. Akad Bakış 56:129-145

Xu G (2007). GPS: Theory, algorithms and applications

Yadav S, Subramanian S (2016). Detection of Application Layer DDoS attack by feature learning using Stacked AutoEncoder. In: 2016 International Conference on Computational Techniques in Information and Communication Technologies, ICCTICT 2016 Proceedings. pp 361-366

Zhang Q, Wang H, Dong J, et al (2017). Prediction of Sea Surface Temperature Using Long Short-Term Memory. IEEE Geosci Remote Sens Lett 14:17451749. doi: 10.1109/LGRS.2017.2733548 